\title{
The effects of physical exercise on metabolic rate and dietary- induced thermogenesis
}

\author{
By M. GLEESON, J. F. BROWN AND J. J. WA RING \\ Biology Division, Preston Polytechnic, Preston PRI 2TQ \\ AND M. J. STOCK \\ Department of Physiology, St. George's Hospital Medical School, University of London, \\ London SWI $70 R G$
}

(Received 8 December 1980 - Accepted 21 September 1981)

\footnotetext{
1. The energy metabolism of ad lib.-fed adult male Wistar rats receiving daily running exercise $\left(0.9 \mathrm{~km} / \mathrm{d} ; 8^{\circ}\right.$ incline) on a motor-driven treadmill, over a period of $56 \mathrm{~d}$, was compared with that of sedentary ad lib.-fed rats and sedentary restricted-fed rats of similar body-weight (approximately $420 \mathrm{~g}$ ).

2. The metabolizable energy of the diet (Oxoid 41B) was $11.44 \pm 0.05 \mathrm{~kJ} / \mathrm{g}$. This value was not affected by restricted feeding $(70 \%$ ad lib.), exercise training or exercise itself.

3. Exercise-trained rats ate $5 \%$ more food than the sedentary ad lib.-fed rats but their equilibrium body-weight was $60 \mathrm{~g}$ lower than that of the latter group.

4. Resting metabolic rate, measured over $22 \mathrm{~h}$ in a respiration chamber was increased by $10 \%$ in exercise-trained animals.

5. Feeding increased energy expenditure (dietary-induced thermogenesis) and this effect was potentiated by performance of an exercise task.

6. Exercise-trained rats exhibited anticipatory rises in energy expenditure (approximately $40 \%$ ) when placed on a stationary treadmill.

7. Treadmill work increased energy expenditure by a factor of $1 \cdot 9-2 \cdot 4$.

8. The energy cost of the exercise, determined by respiration calorimetry was $66-80 \mathrm{~J} / \mathrm{g}$ per $\mathrm{km}$. These energy costs did not account for all the differences observed in food energy consumption of exercise-trained and sedentary rats of equal body-weight.

9. It is concluded that regular physical exercise increases energy expenditure by factors additional to the energy requirement directly related to the physical work. These factors include an increased resting metabolic rate in exercise-trained rats, increased dietary thermogenesis induced by exercise and anticipatory increases in energy metabolism during the period preceding exercise.
}

Metabolic adaptation occurs in man and experimental animals in response to exercise training (Holloszy \& Booth, 1976). Thus the activities of many enzymes involved in energy metabolism are greatly modified and the patterns of storage and mobilization of energy reserves are altered (Taylor et al. 1974; Askew \& Hecker, 1976).

As well as an effect of exercise training, exercise per se may affect energy metabolism in ways other than the direct increase in energy metabolism attributable to muscular contraction. Thus Miller et al. (1967), Bray et al. (1974) and Gleeson et al. (1979) have reported increased dietary-induced thermogenesis during exercise.

In the present experiment the energy metabolism of exercise-trained rats was compared with that of sedentary controls, one group of which was fed ad lib. and the other given only sufficient food to maintain the same body-weight as the exercise-trained rats. For all groups, energy expenditure was measured by indirect calorimetry, at rest and over periods which included treadmill running exercise; and on fed and fasted animals. The experiment was intended to assess the importance of regular exercise to long-term energy balance and was also designed to confirm the effects of exercise on dietary-induced thermogenesis when the latter is measured over a period of several hours following the feeding and exercise treatment. 


\section{EXPER IMENT A L}

\section{Animals and treatments}

Twenty-six male Wistar rats weighing $420 \pm 3 \mathrm{~g}$ at the start of the experiment, were used. Twenty-four of the rats were randomly assigned to three treatments: (1) exercise trained, ad-lib.-fed group receiving a total of forty-eight $1 \mathrm{~h}$ treadmill exercise sessions daily over the 56 day period. (2) sedentary, ad lib.-fed group receiving only eight $1 \mathrm{~h}$ treadmill exercise sessions during the course of measurement of energy expenditure in the respiration chambers. (3) sedentary, restricted-fed group receiving only eight $1 \mathrm{~h}$ treadmill sessions as for group 2 but food restricted so that the animals maintained the same body-weight as the exercise-trained group.

The remaining two rats were killed to determine initial carcass composition.

\section{Feeding and housing}

The rats were given a powdered commercial diet (Oxoid 41B) in two meals provided at 09.00-11.00 hours and 16.00-18.00 hours. Meal-feeding is essential for energy-balance studies in which energy expenditure is related to a measured food intake. The rats were housed in metabolism cages in a room maintained at $24^{\circ}$ and subject to a $12 \mathrm{~h}$ light-dark cycle with darkness between 18.00 and 06.00 hours.

\section{Exercise}

Routine exercise for the exercise-trained group consisted of $1 \mathrm{~h}$ daily running on a motor-driven treadmill set at an angle of $8^{\circ}$ and a speed of $0.9 \mathrm{~km} / \mathrm{h}$. Half the group (four rats) were exercised preprandially (08.00-10.00 hours) and the other half postprandially (11.00-12.00 hours). Within the $56 \mathrm{~d}$ trial the rats in the exercise-trained group completed $48 \mathrm{~h}$ of treadmill running (a total of $42.8 \mathrm{~km}$ horizontal and $6.0 \mathrm{~km}$ vertical).

\section{Metabolizable energy}

Following 4 weeks of training, the metabolizable energy of the diet was determined for all rats on each treatment. The rats were fed quantitatively over a $4 \mathrm{~d}$ period and all faeces and urine produced over this period, including that excreted during treadmill exercise, were collected. The pooled urine and faeces were freeze-dried and their energy content and that of the diet, determined using an adiabatic bomb calorimeter (Gallenkamp).

\section{Energy expenditure}

Two closed-circuit respiration chambers based on the design of Waring \& Brown (1965) were used. One of the chambers contained the motor-driven treadmill. Energy expenditure was calculated from oxygen consumption and carbon dioxide production using the equations of Kleiber (1975) (a) for the fed state:

energy expenditure $(\mathrm{kJ})=\mathrm{mol} \mathrm{O}_{2}(364+113 . \mathrm{RQ})$, where $\mathrm{RQ}$ is respiratory quotient;

(b) for the fasting state:

energy expenditure $(\mathrm{kJ})=\mathrm{mol}_{2}(399 \pm 63 . \mathrm{RQ})$.

The measurements of respiratory exchange were made on groups of four rats (exercisetrained, sedentary or sedentary-restricted) under conditions of rest or treadmill-running exercise and either in the fed or fasted state.

Resting energy expenditure was measured over the $22 \mathrm{~h}$ period 10.00 to 08.00 hours, either in the fasting state (no morning meal) or in the fed state (morning meal at 09.00-10.00 hours). During measurement of energy expenditure in the fed state, measurements were discontinued at 16.30 hours to allow the second meal to be given. Food was removed and respiration measurements recommenced at 17.30 hours. A $1 \mathrm{~h}$ feeding period was used 


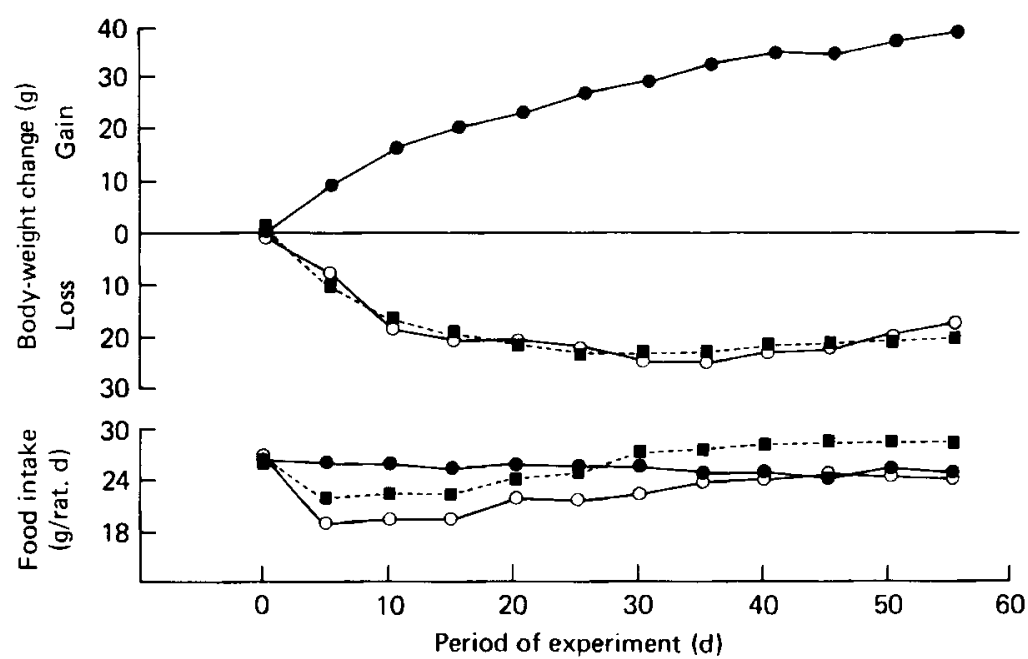

Fig. 1. Effect of exercise training (by daily treadmill running) and food restriction on food intake and

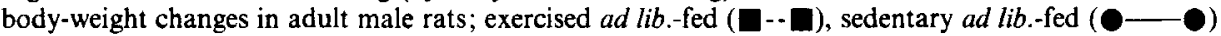
and sedentary restricted-fed $(\mathrm{O}-\mathrm{O})$.

because experience of meal-feeding showed that rats consumed $90 \%$ of their intake in the first hour of a $2 \mathrm{~h}$ feeding period and it was considered desirable to resume measurement of energy expenditure as soon as possible. All data was corrected to a $24 \mathrm{~h}$ basis, the actual periods of measurement being approximately $22 \mathrm{~h}$ for fasted and $20 \mathrm{~h}$ for fed animals.

Energy expenditures of treadmill-exercised animals were measured over the same time period and involved identical fasting or feeding procedures to those employed in the measurements made on resting animals. At 10.00 hours the rats were placed on individual lanes of the treadmill within a respiration chamber and respiratory exchange measurements commenced. After 60 min resting on the treadmill the motor was switched on and the rats exercised for $60 \mathrm{~min}$ at $0.9 \mathrm{~km} / \mathrm{h}$ on an $8^{\circ}$ incline. At the end of the exercise period the motor was switched off and measurement of recovery and subsequent resting expenditure was made for a further $20 \mathrm{~h}$. Following the procedure described for the resting animals, measurements were interrupted for the fed groups between 16.30 and 17.30 hours. All the exercise regimens using the respiration chambers involved postprandial exercise.

\section{Carcass analysis}

At the end of the experiment all the rats were weighed, killed and the carcasses frozen prior to mincing and sampling. Freeze-dried samples were analysed for total energy (Gallenkamp adiabatic bomb calorimeter).

\section{RESULTS}

Food consumption and body-weight

The effects of regular exercise training and food restriction, on food intake and body-weight are shown in Fig. 1.

The initial period of training caused a significant $(P<0.01)$ reduction in food intake and body-weight, compared with sedentary controls. However after 3 weeks training, food intake returned to control levels and after 5 weeks training, the trained animals consumed $25 \%$ more food daily per $100 \mathrm{~g}$ body-weight, than the controls. However, the body-weight 
Table 1. Effects of preprandial and postprandial regularly-enforced treadmill exercise on food intake $(\mathrm{g} / \mathrm{d})$ and meal size of rats

(Mean values with their standard errors for the $56 \mathrm{~d}$ experimental period. Trained rats were exercised daily for $60 \mathrm{~min}$, either immediately before their morning meal (preprandial exercisers) or immediately after their morning meal (postprandial exercisers))

\begin{tabular}{|c|c|c|c|c|c|c|}
\hline & \multirow[b]{3}{*}{$n$} & \multicolumn{5}{|c|}{ Food intake $(\mathrm{g} / \mathrm{d})$} \\
\hline & & \multicolumn{2}{|c|}{$\begin{array}{c}\text { Morning meal } \\
(09.00-11.00 \\
\text { hours })\end{array}$} & \multicolumn{2}{|c|}{$\begin{array}{c}\text { Evening meal } \\
(16.00-18.00 \\
\text { hours })\end{array}$} & \multirow[b]{2}{*}{ Tota } \\
\hline & & Mean & SE & Mean & SE & \\
\hline $\begin{array}{l}\text { Preprandial exercisers } \\
\text { (exercised } 08.00-09.00 \text { hours) }\end{array}$ & 4 & $10-9$ & $0 \cdot 3$ & $15 \cdot 1$ & 0.4 & $26 \cdot 0$ \\
\hline $\begin{array}{l}\text { Postprandial exercisers } \\
\text { (exercised } 11.00-12.00 \text { hours) }\end{array}$ & 4 & $13 \cdot 1$ & 0.3 & $13 \cdot 3$ & $0 \cdot 4$ & $26 \cdot 4$ \\
\hline Sedentary $a d$-lib-fed & 8 & $14 \cdot 7$ & $0 \cdot 3$ & $10 \cdot 2$ & 0.4 & $25 \cdot 0$ \\
\hline Sedentary, restricted-fed & 8 & $12 \cdot 6$ & 0.4 & $9 \cdot 0$ & $0 \cdot 4$ & $21 \cdot 6$ \\
\hline
\end{tabular}

Table 2. Effect of training, exercise and food restriction on metabolizable energy content of diet (Oxoid 4lB)

(Mean values with their standard errors for eight rats/treatment)

\begin{tabular}{|c|c|c|c|c|c|c|c|c|c|}
\hline & & \multirow{2}{*}{\multicolumn{2}{|c|}{$\begin{array}{l}\text { Food intake } \\
\quad(\mathrm{g} / \mathrm{rat})\end{array}$}} & \multirow{2}{*}{\multicolumn{2}{|c|}{$\begin{array}{l}\text { Energy intake } \\
(\mathrm{kJ} / \mathrm{rat})\end{array}$}} & \multicolumn{4}{|c|}{$\begin{array}{l}\text { Energy intake excreted } \\
\text { in faeces \& urine }\end{array}$} \\
\hline & & & & & & \multicolumn{2}{|c|}{$(\%)$} & \multicolumn{2}{|c|}{$(\mathrm{kJ} / \mathrm{g})$} \\
\hline & & Mean & $\mathrm{SE}$ & Mean & SE & Mean & $\mathbf{S E}$ & Mean & SE \\
\hline \multirow[t]{2}{*}{ Trained ad lib.-fed: } & Resting & $96 \cdot 0$ & $1 \cdot 5$ & 1531 & 25 & $28 \cdot 0$ & $0 \cdot 3$ & $11 \cdot 41$ & 0.05 \\
\hline & Exercised & 94.9 & $1 \cdot 5$ & 1504 & 24 & $27 \cdot 2$ & 0.8 & $11 \cdot 52$ & $0 \cdot 12$ \\
\hline Sedentary ad lib.-fed & & 91.6 & $1 \cdot 2$ & 1451 & 18 & $27 \cdot 1$ & 0.6 & $11 \cdot 54$ & $0 \cdot 10$ \\
\hline Sedentary restricted-fed & & $68 \cdot 2$ & $0 . \overline{9}$ & 1080 & 14 & $28 \cdot 1$ & $0 \cdot 4$ & $11 \cdot 39$ & 0.08 \\
\hline
\end{tabular}

of the exercise-trained animals equilibrated at a level approximately $60 \mathrm{~g}$ below that of the sedentary controls.

The timing of the exercise in relation to feeding, did not affect total food consumption. Table 1 shows that, while preprandial exercise lowered the size of the morning meal, there was a compensatory increase in the afternoon meal.

\section{Metabolizable energy}

The results are summarized in Table 2. The mean ( \pm SE) ME content of the diet was $11.44 \pm 0.05 \mathrm{~kJ} / \mathrm{g}$ and none of the treatments significantly affected this value.

\section{Metabolic rate and thermic responses to food and exercise}

The energy expenditures of resting or exercising rats either in the fed or fasted state are given in Table 3.

Values for fasting resting energy expenditure corrected for differences in body-weight were $19 \cdot 8,18 \cdot 2$ and $18 \cdot 1 \mathrm{~kJ} / \mathrm{kg}$ per $\mathrm{h}$ for trained, sedentary and sedentary-restricted rats 
Table 3. Effect of exercise training and food restriction on metabolic rate, in the fed and fasting state

(Mean values with their standard errors for eight observations on groups of four rats. Measurements made at rest, or including a standardized exercise task during the $20-22 \mathrm{~h}$ period of measurement)

\begin{tabular}{|c|c|c|c|c|c|c|c|c|c|c|c|}
\hline & \multirow{4}{*}{$\begin{array}{c}\text { Mean } \\
\text { body-wt } \\
\text { (g) }\end{array}$} & \multicolumn{9}{|c|}{ Energy expenditure ( $\mathrm{kJ} /$ rat per d) } & \multirow{4}{*}{$\begin{array}{c}\text { Thermi } \\
\text { effect }\end{array}$} \\
\hline & & \multicolumn{4}{|c|}{ Resting } & \multicolumn{5}{|c|}{ Exercised } & \\
\hline & & \multicolumn{2}{|c|}{ Fasting } & \multicolumn{2}{|c|}{ Fed } & \multirow{2}{*}{$\begin{array}{c}\text { Thermic } \\
\text { effect }\end{array}$} & \multicolumn{2}{|c|}{ Fasting } & \multicolumn{2}{|c|}{ Fed } & \\
\hline & & Mean & SE & Mean & SE & & Mean & SE & Mean & $\mathrm{SE}$ & \\
\hline Trained ad lib.-fed & 416 & 198 & 2 & 216 & 2 & 18 & 223 & 1 & 246 & 2 & 23 \\
\hline Sedentary $a d$ lib.-fed & 441 & 193 & 1 & 205 & 2 & 12 & 218 & 1 & 240 & 2 & 22 \\
\hline Sedentary restricted-fed & 418 & 182 & 2 & 195 & 2 & 13 & 208 & 2 & 231 & 2 & 22 \\
\hline
\end{tabular}

Table 4. Effect of a standardized exercise task on changes in energy expenditure with time of untrained rats, in the fed and fasting state

(Mean values with their standard errors. Each value is the mean of sixteen observations on groups of four rats. The exercise period was $11.00-12.00$ hours)

\begin{tabular}{|c|c|c|c|c|c|c|c|c|}
\hline \multirow{4}{*}{$\begin{array}{c}\text { Time of } \\
\text { day (hours) }\end{array}$} & \multicolumn{8}{|c|}{ Energy expenditure $(\mathrm{kJ} / \mathrm{kg} / \mathrm{h})$} \\
\hline & \multicolumn{4}{|c|}{ Resting } & \multicolumn{4}{|c|}{ Exercised } \\
\hline & \multicolumn{2}{|c|}{ Fasting } & \multicolumn{2}{|c|}{ Fed } & \multicolumn{2}{|c|}{ Fasting } & \multicolumn{2}{|c|}{ Fed } \\
\hline & Mean & SE & Mean & SE & Mean & SE & Mean & $\mathrm{SE}$ \\
\hline $10.00-11.00$ & $2 \cdot 30$ & $0 \cdot 03$ & $2 \cdot 88$ & $0 \cdot 05$ & $2 \cdot 58$ & $0 \cdot 05$ & $3 \cdot 45$ & $0 \cdot 06$ \\
\hline $11.00-12.00$ & $1 \cdot 79$ & $0 \cdot 01$ & 1.92 & 0.02 & 3.49 & 0.08 & $4 \cdot 77$ & 0.09 \\
\hline $12.00-16.00$ & $1 \cdot 70$ & $0 \cdot 01$ & $1 \cdot 84$ & $0 \cdot 01$ & $2 \cdot 12$ & 0.01 & $2 \cdot 28$ & $0 \cdot 02$ \\
\hline $16.00-18.00$ & $1 \cdot 70$ & 0.01 & \multicolumn{2}{|c|}{ Feeding } & $2 \cdot 07$ & 0.01 & \multicolumn{2}{|c|}{ Feeding } \\
\hline $18.00-06.00$ & $1 \cdot 86$ & $0 \cdot 02$ & 1.95 & $0 \cdot 01$ & 1.95 & 0.01 & $2 \cdot 07$ & 0.01 \\
\hline $06.00-08.00$ & $1 \cdot 65$ & 0.01 & 1.66 & $0 \cdot 01$ & 1.64 & 0.01 & 1.68 & 0.01 \\
\hline
\end{tabular}

respectively. On this basis resting energy expenditure was significantly $(P<0.05)$ greater for exercise-trained than for habitually-sedentary rats. The difference (in resting energy expenditure) was $7 \%$ in the fasted state and increased to $10 \%$ in fed rats.

In order to ensure reasonably equal food energy intakes during measurements of fed energy expenditure in the respiration chambers, the rats were offered less food on these days than they would normally consume. The over-all mean daily metabolizable energy consumption over $56 \mathrm{~d}$ was $280 \mathrm{~kJ} /$ rat but on the experimental days only $180 \mathrm{~kJ} / \mathrm{rat}$ was offered and this was usually consumed completely. Feeding produced a thermic response in each group varying from 7 to $13 \%$ of the metabolizable energy intake. The thermic responses were increased on average by a factor of approximately 1.6 when a period of treadmill exercise was included. There were also indications that exercise training produced greater thermic responses to feeding although this result was only obtained in experiments on resting animals.

Energy expenditure varied considerably throughout the day. Values for sedentary and exercise-trained rats are presented in Tables 4 and 5 respectively. There was no significant 
Table 5. Effect of a standardized exercise task on changes in energy expenditure with time of trained rats, in the fed and fasting state

(Mean values with their standard errors. Each value is the mean of eight observations on groups of four rats. The exercise period was $11.00-12.00$ hours)

\begin{tabular}{|c|c|c|c|c|c|c|c|c|}
\hline \multirow{4}{*}{$\begin{array}{c}\text { Time of } \\
\text { day (hours) }\end{array}$} & \multicolumn{8}{|c|}{ Energy expenditure $(\mathrm{kJ} / \mathrm{kg} / \mathrm{h})$} \\
\hline & \multicolumn{4}{|c|}{ Resting } & \multicolumn{4}{|c|}{ Exercised } \\
\hline & \multicolumn{2}{|c|}{ Fasting } & \multicolumn{2}{|c|}{ Fed } & \multicolumn{2}{|c|}{ Fasting } & \multicolumn{2}{|c|}{ Fed } \\
\hline & Mean & SE & Mean & SE & Mean & SE & Mean & $\mathbf{S E}$ \\
\hline $10.00-11.00$ & $2 \cdot 41$ & 0.05 & $3 \cdot 36$ & $0 \cdot 05$ & $3 \cdot 56$ & 0.08 & 4.69 & 0.07 \\
\hline $11.00-12.00$ & 1.99 & $0 \cdot 04$ & $2 \cdot 38$ & $0 \cdot 02$ & $3 \cdot 79$ & 0.02 & $5 \cdot 29$ & $0 \cdot 13$ \\
\hline $12.00-16.00$ & 1.91 & 0.02 & $2 \cdot 05$ & 0.02 & $2 \cdot 30$ & 0.03 & $2 \cdot 45$ & 0.04 \\
\hline $16.00-18.00$ & 1.94 & $0 \cdot 02$ & \multicolumn{2}{|c|}{ Feeding } & $2 \cdot 24$ & 0.02 & \multicolumn{2}{|c|}{ Feeding } \\
\hline $18.00-06.00$ & $2 \cdot 01$ & 0.02 & $2 \cdot 11$ & $0 \cdot 02$ & $2 \cdot 04$ & $0 \cdot 01$ & $2 \cdot 16$ & $0 \cdot 02$ \\
\hline $06.00-08.00$ & 1.85 & 0.01 & 1.85 & 0.01 & $1 \cdot 84$ & 0.01 & 1.86 & 0.01 \\
\hline
\end{tabular}

difference between the results for the sedentary and sedentary-restricted groups or between the preprandial and postprandial exercise-trained groups and therefore the results for these groups have been combined.

It can be seen that metabolic rate during the first hour of measurement was generally high. It was particularly high for fed animals and also for exercise-trained animals when resting on the treadmill. The latter result indicated an anticipatory rise in metabolism before exercise, Initially habitually-sedentary rats did not show the response but by the end of the experiment a small anticipatory rise was noted (Table 4) reflecting their limited experience on the treadmill.

\section{Energy balance}

The results of the $56 \mathrm{~d}$ energy balance experiment are presented in Table 6 . The work done against gravity during the treadmill exercise was calculated using the formula:

work $(\mathrm{kJ})=$ body-weight $(\mathrm{kg}) \times$ distance run $(\mathrm{km}) \times$ sine of the angle of inclination $\times 9 \cdot 81$.

It is well known however, that increased energy expenditure attributable to low-angle treadmill work, is more related to the horizontal than the vertival distance moved. The results of Shepherd \& Gollnick (1976) indicate that horizontal running involves an extra energy consumption of $46 \mathrm{~J} / \mathrm{g}$ per $\mathrm{km}$ while Brooks \& White (1978) (working with young $150 \mathrm{~g}$ rats) showed that increasing the angle of elevation by $8^{\circ}$ increased energy expenditure by approximately $10 \%$. In the present experiment the increase in energy expenditure due to treadmill work can be calculated from the values in Table 3:

energy expenditure due to treadmill work = daily energy expenditure including $1 \mathrm{~h}$ treadmill running - daily energy expenditure at rest.

The results obtained for $8^{\circ}$ running were 66,73 and $80 \mathrm{~J} / \mathrm{g}$ per $\mathrm{km}$ (distance run) for trained, sedentary ad-lib.-fed and sedentary restricted-fed rats respectively. The results are about $30 \%$ higher than the values obtained from the literature. This is probably due to the fact that the energy expenditure due to exercise was measured over a long period following cessation of the exercise. The values presented in Tables 4 and 5 show that a long period of measurement is a necessary feature of such experiments.

The energy expended (energy intake - energy retained) calculated from food and carcass 
Table 6. Energy balance results from exercise trained, sedentary and restricted-sedentary rats from day 0 to day 56 of the study

(Mean values with their standard errors given in parentheses where appropriate)

\begin{tabular}{|c|c|c|c|c|}
\hline & \multicolumn{2}{|c|}{ Exercise-trained } & \multirow[b]{2}{*}{ Sedentary } & \multirow{2}{*}{$\begin{array}{l}\text { Restricted- } \\
\text { sedentary }\end{array}$} \\
\hline & Preprandial & Postprandial & & \\
\hline Mean body-wt* (g) & 415 & 418 & 441 & 418 \\
\hline Body-wt changet $(\mathrm{g})$ & $-22(5)$ & $-17(4)$ & $+33(6)$ & $-16(3)$ \\
\hline Energy intake $(\mathrm{kJ})$ & $16646(200)$ & $16902(260)$ & $15997(350)$ & $13809(140)$ \\
\hline Total $(\mathbf{k J} / \mathbf{k g}$ per d) & 72 & 72 & 65 & 59 \\
\hline Final body energy $(\mathbf{k J})$ & $3490(70)$ & $3730(60)$ & $4670(90)$ & $3730(50)$ \\
\hline Body energy change $(\mathrm{kJ})$ & $-310(70)$ & $-71(60)$ & $+873(90)$ & $-70(50)$ \\
\hline No. of treadmill runs (days $0-56$ ) & 48 & 48 & 8 & 8 \\
\hline Work done against gravity $\ddagger(\mathrm{kJ})$ & 24 & 24 & 4 & 4 \\
\hline Energy expended $(\mathrm{kJ})$ (intake - retained) & 16956 & 16973 & 15124 & 13879 \\
\hline Energy expended $(\mathrm{J} / \mathrm{kg} / \mathrm{h})$ & $30 \cdot 4$ & $30 \cdot 0$ & $25 \cdot 5$ & $24 \cdot 7$ \\
\hline
\end{tabular}

* Sum of daily wt over $56 \mathrm{~d} \div 56$.

+ Final body-wt -initial body-wt.

$\ddagger$ Calculated from: work $(\mathbf{k J})=$ body-wt $(\mathrm{kg}) \times$ distance run $(\mathrm{km}) \times$ sine of angle of inclination $\times 9.81$.

energy is approximately equivalent to the energy available for maintenance since the amounts of tissue energy gain and loss were relatively small. It can be seen (Table 6) on this basis, that the maintenance requirements of the trained rats are very much greater than those of the sedentary rats, despite the fact that the amount of treadmill work imposed was relatively small. This suggests that regular physical exercise may increase energy expenditure by factors not directly related to the energy requirement for mechanical work.

\section{DISCUSSION}

The results obtained by indirect calorimetery indicate that in energy-balance studies, long-term measurements are required, preferably conducted over at least $24 \mathrm{~h}$. Results for the first hour in the respiration chambers are always higher and more variable than for subsequent hours and furthermore the effects of feeding and exercise may extend for up to $10 \mathrm{~h}$ beyond the feeding or exercise period. Comparison of energy expenditures calculated from the energy-balance study (Table 6) with those calculated from results obtained with the respiration chamber (Table 3) showed that the latter values were approximately $20 \%$ less than the former values. In the present experiment this finding may have been partly due to the fact that the feeding periods were excluded from the periods of measurement in the respiration chambers, but it may also reflect the rather monotonous conditions of life in the respiration chambers. The resting $\mathrm{O}_{2}$ consumptions obtained in these experiments were similar to those obtained by other workers and it would appear that lowered energy expenditure is a feature of animal calorimetry.

In spite of the previously-mentioned reservations, the energy expenditures obtained from the balance measurements showed the same relative differences for the various experimental groups as those obtained by $20-22 \mathrm{~h}$ measurements in the respiration chambers. Using indirect calorimetry, the weighted means for trained, sedentary and sedentary-restricted rats were respectively $23.8,19.6$ and $19.7 \mathrm{~kJ} / \mathrm{kg}$ per $\mathrm{h}$. These compare to means of $30 \cdot 2,25 \cdot 5$ and $24.7 \mathrm{~kJ} / \mathrm{kg}$ per h obtained from the $56 \mathrm{~d}$ energy-balance trial (Table 6 ). Thus, by both methods, the energy expenditure of the trained rats was $20 \%$ greater than that of sedentary rats of equal body-weight. 
The exercise training programme adopted for the present study could be regarded as of low intensity on the basis that it required only approximately $30 \%$ of the rats' maximum aerobic capacity (Pasquis et al. 1970) and the metabolic rate was increased by only 1.9-2.1 fold above resting values. Nevertheless, it produced a significant initial fall in food intake and a permanent reduction in body-weight. After 3 weeks of exercise-training, food consumption equalled and subsequently became greater than that of the sedentary controls while body-weight fell by $5 \%$. At the end of the $56 \mathrm{~d}$ experimental period, the exercise-trained rats, despite being $11 \%$ lighter, had consumed $4.9 \%$ more food than the sedentary controls and $18.6 \%$ more food than the sedentary-restricted group of equal body-weight.

It might be assumed that the effect of training on energy balance was due to the energy cost of activity but only a small proportion of the increased energy expenditure of the trained rats was attributable to the treadmill work per se. For example, the trained group consumed $3000 \mathrm{~kJ}$ more ME than the sedentary-restricted group of equal body-weight. The trained group performed $36 \mathrm{~km}$ more treadmill work than the sedentary rats but taking the figure of $66 \mathrm{~J} / \mathrm{g}$ per $\mathrm{km}$ obtained from the respiration chamber work and a mean body-weight of $416 \mathrm{~g}$, this would account for an additional energy expenditure of approximately $100 \mathrm{~kJ}$.

A large part of the difference in energy expenditure of trained and untrained rats can be ascribed to increases in resting metabolic rate $(10 \%)$ and changes in the thermic response to food. It is apparent that the effects of even mild physical exercise extend well beyond the period of the exercise and this may lead to low estimates of the energy cost of exercise and an under-rating of exercise as a factor influencing energy balance.

The interactions between exercise and the thermic response to feeding noted by previous workers (Miller et al. 1967; Bray et al. 1974; Gleeson et al. 1979) are confirmed in the present study. On average, the thermic effect of food in resting rats amounted to $14 \mathrm{~kJ} / \mathrm{rat}$ per d ( $7 \%$ of fasting metabolic rate) whilst in rats exercised for $1 \mathrm{~h}$ the value increased $(P<0.05)$ to $23 \mathrm{~kJ} /$ rat per $\mathrm{d}(11 \%$ of fasting metabolic rate). An effect of exercise training on thermic responses was also noted in the present study, with trained rats exhibiting greater resting responses to food than sedentary rats. The metabolic basis for these acute and chronic effects of exercise on postprandial metabolism is unknown but it is possible that they result from changes in the activity of the sympathetic nervous system. Sympathetic activity is increased by exercise and it has recently been suggested that diet-induced thermogenesis results from sympathetic activation of metabolism, Rothwell \& Stock (1979).

It was also observed that exercise-trained rats anticipating exercise could increase their energy expenditure substantially in the pre-exercise period although they did not appear to be abnormally physically active compared to when measurements were made at rest. This factor may well have contributed significantly to the high energy cost of the treadmill exercise and it is interesting to speculate on the mechanism. Sympathetic activity may be involved here also or, as Newsholme (1978) has suggested, exercise training may result in increased activity of substrate cycles, an adaptation which may be associated with increased efficiency of metabolic regulation, albeit at the cost of somewhat lowered efficiency of energy utilization. Anticipated stress, as a factor affecting energy expenditure, has obvious implications for human experimentation and although preliminary investigations have been undertaken by Blaza \& Garrow (1980), it deserves more attention.

It is concluded that exercise training increased energy expenditure in several ways. These included the direct energy cost of the exercise, increases in resting metabolic rate and exercise-induced dietary thermogenesis and anticipatory increases in energy metabolism in the period preceding exercise. 


\section{REFERENCES}

Askew, E. W. \& Hecker, A. L. (1976). J. Nutr. 106, 1351.

Blaza, S. E. \& Garrow, J. S. (1980). Proc. Nutr. Soc. 39, 13A.

Bray, G. B., Whipp, B. J. \& Koyal, S. N. (1974). Am. J. clin. Nutr. 27, 254.

Brooks, G. A. \& White, T. P. (1978). J. Appl. Physiol. 45, 1009.

Gleeson, M., Brown, J. F., Waring, J. J. \& Stock, M. J. (1979). Proc. Nutr. Soc. 38, 8A.

Holloszy, J. O. \& Booth, F. W. (1976). A. Rev. Physiol. 38, 273.

Kleiber, M. (1975). The Fire of Life. New York: R. E. Krieger Publishing Co. Inc.

Miller, D. S., Mumford, P. \& Stock, M. J. (1967). Am. J. clin. Nutr. 20, 1223.

Newsholme, E. A. (1978). Biochem. Soc. Symp. 43, 183.

Pasquis, P.. Lacaisse, A. \& Dejours, P. (1970). Respirat. Physiol. 9, 298.

Rothwell, N. J. \& Stock, M. J. (1979). Nature, New Biol. 281, 31.

Shepherd, R. E. \& Gollnick, P. D. (1976). Pflügers Arch. 362, 219.

Taylor, A. W., Cary, S., McNulty, M., Garrod, J. \& Secord, D. C. (1974). J. Nutr. 104, 218.

Waring, J. J. \& Brown, W. O. (1965). J. agric. Sci., Camb. 65, 139. 